\title{
Experience of practices of urban territorial Planning of Belarus
}

\author{
Tatyana Panchenko ${ }^{1, *}$ \\ ${ }^{1}$ Brest State Technical University, 224017, Moskovskaya 267, Brest, Belarus
}

\begin{abstract}
Rapid urbanization is one of the most significant global trends in an increasingly interconnected world. This means a new global approach to assessing the role of cities in the economy, climate change, use and consumption of natural resources as well as their contribution to social and innovative development. Globalization and large-scale urbanization, combined with smart technologies, are rapidly changing the world around us, the structure of economic activity and the way people live. After the publication in 1987 the report "Our Common Future" by the UN World Commission on Environment and Development, the conference in Rio de Janeiro in 1992 and other international initiatives by 2008 declarations, framework directives, strategies and methodologies for sustainable development and the creation of "green" economy were adopted.

Taking into account the historically high level of urbanization in our country $(70.08 \%$ of the population lives in cities) [1], in recent years, legislative instruments of the local (city) level, aimed at using the tools of integrated territorial planning, have begun to form. The article describes the experience of urban territorial planning practices in Novogrudok, Polotsk, Novopolotsk and Brest for which local strategic documents of a new type have now been developed: "Green Urban Development Plans" and the Concept of Smart Sustainable Development.
\end{abstract}

Keywords: sustainable development, urban planning, strategic planning, Urban settlements, Republic of Belarus

\section{Introduction}

The world experience of recent decades shows the rapid development and diversity of urban development models and the lack of universal tools. At the same time, the fact of the common genesis of the developed largest cities-megalopolises and, accordingly, their experience and practices, as developing cities in the urbanization stage are already in different socio-economic, climatic and environmental conditions.

In 2017, the Republic of Belarus adopted the National Strategy for Sustainable SocioEconomic Development of the Republic of Belarus until 2030, the National Action Plan for the Development of a Green Economy in Belarus. A number of Belarusian cities have joined the European initiative "Covenant of Mayors on Climate and Energy" (now there are

\footnotetext{
*Corresponding author: tapanchenko46@gmail.com
} 
53 cities). This served as a starting point for finding tools, models, creating framework documents and plans for the sustainable development of urban systems and developing the experience of Belarusian cities. At the same time, the analysis of the practices of strategic planning of urban systems and their development allows the cities of Belarus to choose those methodologies and tools of integrated development which taking into account the historically high level of urbanization will allow integrating spatial, environmental, sociocultural, economic factors, urban systems and institutional aspects in such a way as to achieve a new quality of economic and social development while maintaining and developing the accumulated human capital.

\section{Methods}

The study used a systemic and comparative method, natural, graphic-analytical and quantitative research methods.

\section{Results}

Sustainable development is based on rational management and intensive land use, an efficient energy and transport system, compactness of living and population density, territorial, functional and social integration, maintaining the integrity and viability of biological and physical natural systems in order to achieve long-term effects. Despite the fact that the tasks of sustainable development are global in nature, the strategies for achieving them at the local level are largely local and, therefore, differ in terms of conditions and content depending on the region and city.

The successful development of cities in the modern period around the world is determined by a long-term, holistic, multidimensional and multifunctional approach to urban development which allows integrating spatial, environmental, sociocultural, economic factors, urban systems and institutional aspects in such a way that they mutually reinforce each other, ensuring synergistic effect of combining energy and financing in one direction. Planning has its general goals, objectives and varieties but the form that they acquire is determined by the social conditions and traditions of specific cities.

The UN-Habitat report, Planning for Sustainable Cities: A Global Report on Human Settlements 2009 [2], provides a rationale for urban planning as a means of addressing the challenges of $21 \mathrm{st}$ century cities and improving the quality of sustainable urban development: "Urban planning is a conscious joint activities related to the creation or change of the appearance of a small or large city, urban area or a wider territory as well as with the implementation of the results of such activities, taking into account the priorities regarding investments in the development of the territory, environmental protection measures, new and reconstructed areas of the settlement, financing of development basic infrastructure and principles of regulation of the use of the territory "[2]. The new system of urban planning should: take into account existing problems in the field of ecology, social inequality and contribute to their solution; focus on the fulfillment of national obligations under international treaties (conventions); comply with the implementation of the constitutional rights of citizens, including those with disabilities; be flexible and, if necessary, reorganize to solve urgent problems of the local level; promote the consolidation of the local community through open dialogue with representatives of stakeholders; be aligned with budget, strategic spatial planning plans and land use systems; include monitoring and evaluating city plans.

Thus, the concepts of territorial development and strategies for their implementation reflect the context, preconditions, priorities and needs, in particular, in the social 
environment (for example, social justice, cultural identity and cultural traditions, cultural heritage, human health, safety and comfort, and social infrastructure). Urban development planning practices are aimed at ensuring openness and security, increasing the attractiveness of cities for life and investment, stimulating development processes and competition. The concepts of urban development can be simultaneously quite diverse and similar to each other, since the biggest problems of cities are simultaneously quite diverse and similar to each other: lack of resources, low rates of economic development, social isolation, climate change and the danger of environmental disasters.

This is an extremely urgent and difficult task that must be solved jointly by residents and city leaders in order to ensure a high quality of life and urban environment in the long term, and a balance of natural and anthropogenic factors. It also addresses the broader question of how to transform a city into a stable political, economic and ecological system, as well as how this city-system will be embedded and can increase equity, inclusiveness, sustainability and environmental friendliness in the country and the world.

Foreign experience in the formation and implementation of strategic documents for territorial planning is very wide. There is currently no generally accepted definition of a "green" city. However, practice shows that in the global experience, more and more attention is paid to the urban environmental agenda and focuses on "green" decentralized integrated solutions and complex tools, creating new values and new opportunities for business and society for citizens, effectively using all tangible and intangible assets, providing productive, inclusive and sustainable economic activities. This scenario forms a system of principles that include an integrated approach, a combination of regional and sectoral aspects of management, overcoming departmental (sectoral) disunity, building up the own potential of cities and moving to indicative planning and assessment methods.

The development in Belarus of the European Initiative "Covenant of Mayors on Climate and Energy" in order to reduce GHG emissions by at least $20 \%$ compared to the base year stimulates city administrations to fundamentally change approaches and practices of urban planning, developing innovative integrated approaches and interdepartmental cooperation, taking into account future needs.

In 2016, the European Bank for Reconstruction and Development (EBRD) launched its largest Green Cities initiative to address urban climate change challenges. Acting according to the proposed methodology (based on the "load-state-response" framework concept), city administrations develop "Green Action Plans", the structure and solutions of which cover local environmental priorities, are based on a set of indicators that is unique for each city and contain the implementation timeline and methodology for monitoring their implementation [3].

In 2017-2018 under the expert support of the UNDP Project "Belarus: Support for Green Urban Development in Small and Medium-Sized Cities of Belarus (Green Cities)", "Plans of Green Cities"(PGC) were developed in our country for Novogrudok, Polotsk and Novopolotsk. All of them are participants in the Covenant of Mayors on Climate, their Green Action Plans (GAPs) are strategic documents that define the long-term vision of a green city, strategic goals for each priority area (perspective 10-15 years), and also serve as the basis for decision-making in planning investments and operational work of city administrations in the medium term (3-5 years) [3].

The Green Action Plans for Novogrudok, Polotsk and Novopolotsk were developed based on an analysis of long-term and medium-term documents adopted at the republican, regional and local levels, existing external and internal prerequisites, trends and competitive advantages. They have a general structure, including an analysis of the current state (city passport, analytical overview and profile of the city, analysis of the spatial structure); description of the Mission, Vision and Development Goals; Urban space transformation 
strategy (spatial development aspects, sectoral strategies, road map and funding sources); a set of actions (localization of green actions) on the territory of the city [4].

Each of the cities formed its own scenarios (for example, for Novogrudok, on the basis of a "base" line, active, advanced and prevailing development for various sectors in terms of their impact on environmental aspects and for Novopolotsk - "monoindustrial development", "multi-industrial development "). Determination of priority directions and areas, strategic goal, Mission and Vision of the city were formulated based on the results of a survey of city residents and consultations with experts, representatives of the administration and determine the Local agenda and purpose of the city.

The spatial development strategies outlined in the PGC are based on the principles of effective land use, form the preconditions for the transition to the concept of a recoverable, smart, convenient city, the implementation of the urban planning policy of transit-oriented development, the integrated improvement of developed territories, the preservation of historical heritage, the formation of a unified water-green system, development infrastructure for a new type of economy - closed type.

For a set of actions for the implementation of urban development priorities for each of the cities a system of complex indicators has been assembled with their subsequent monitoring. The consistent implementation of the Green Urban Planning presupposes targeted interventions in the most problematic or, on the contrary, prepared areas of the city to launch its green development, therefore such points of growth and pilot development projects were identified in cities [4].

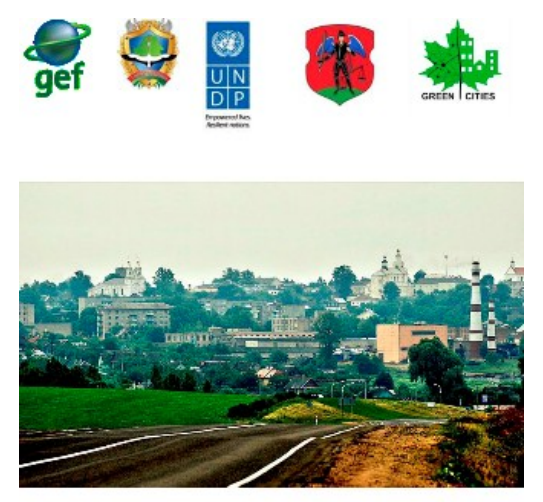

\section{Новогрудок-2040}
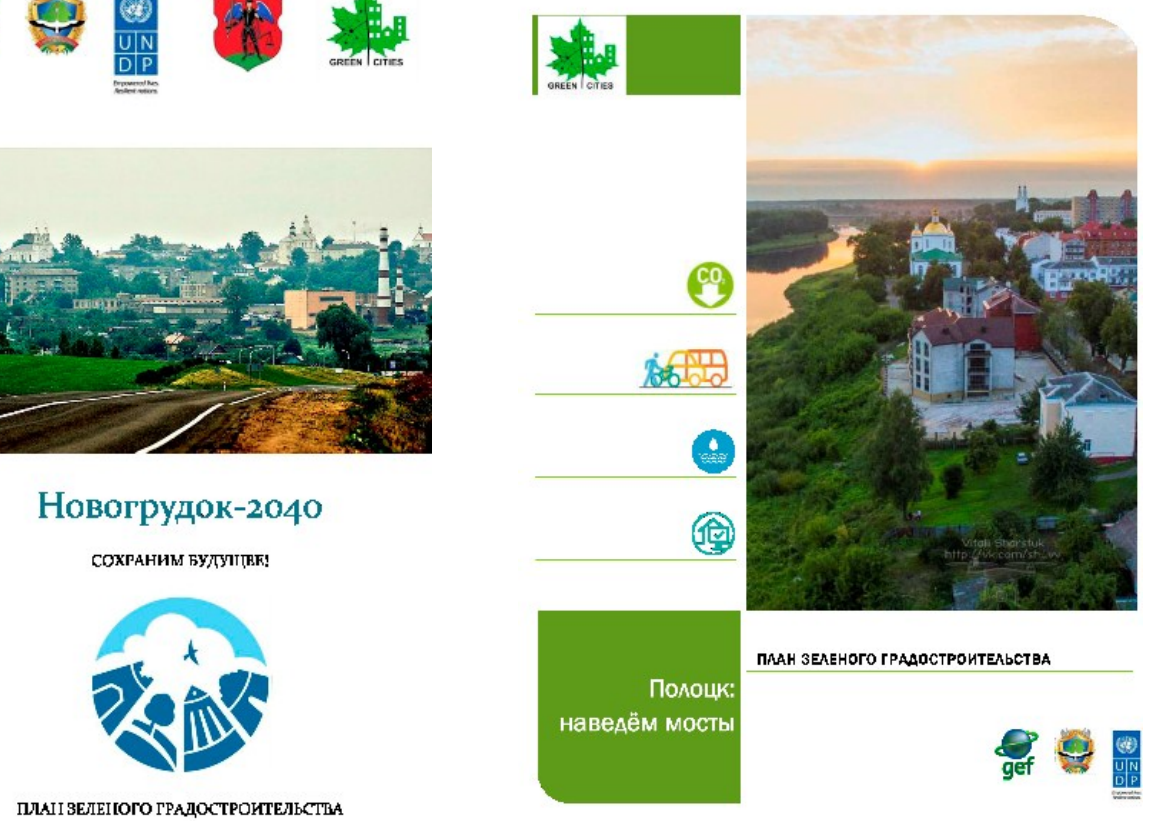

Fig. 1. Plans for green urban development in Polotsk and Novogrudok [4]

Brest joined the Covenant of Mayors movement on October 26, 2015. In this regard, one of the activities of the National Action Plan for the Development of the Green Economy in Belarus until 2020 (approved by the Resolution of the Council of Ministers of the Republic of Belarus No. 1061 on December 21, 2016) [5] was the development and implementation of the Concept Brest: Symbio City 2050. 
Concept "Brest: Symbio City 2050" was developed to accomplish these tasks - a model of smart sustainable urban development based on the possibilities of synergistic interaction of six urban systems (transport (urban mobility); energy and climate; architecture and "green culture"; waste; water supply and sanitation, biodiversity and landscape) while providing economic, social and environmental benefits and phasing in its implementation in the short, medium and long term. For each of the areas of the Concept, fundamental (general and local) goals and objectives are collected, a set of indicators is determined (taking into account the methods of the EBRD, U4SSC, ISO and TNLA RB) and the localization of pilot projects for spatial development.

The strategic goals of the concept were:

- development of a new planning model for the integrated development of the city of Brest in the short, medium and long term based on sustainable principles, using the possibilities of symbiosis of the main urban systems, introducing the decarbonization of infrastructure systems, ensuring a stable improvement in the quality of life of citizens and future generations, as well as increasing the sustainability of the community and stimulating innovative and technological activities.

- creating a basis for dialogue, partnership and cooperation with all stakeholders, actors and policy-makers aimed at creating sectoral and integrated strategies related to the social and economic systems of the city, as well as for interdisciplinary and sectoral analysis of sustainability at all levels.

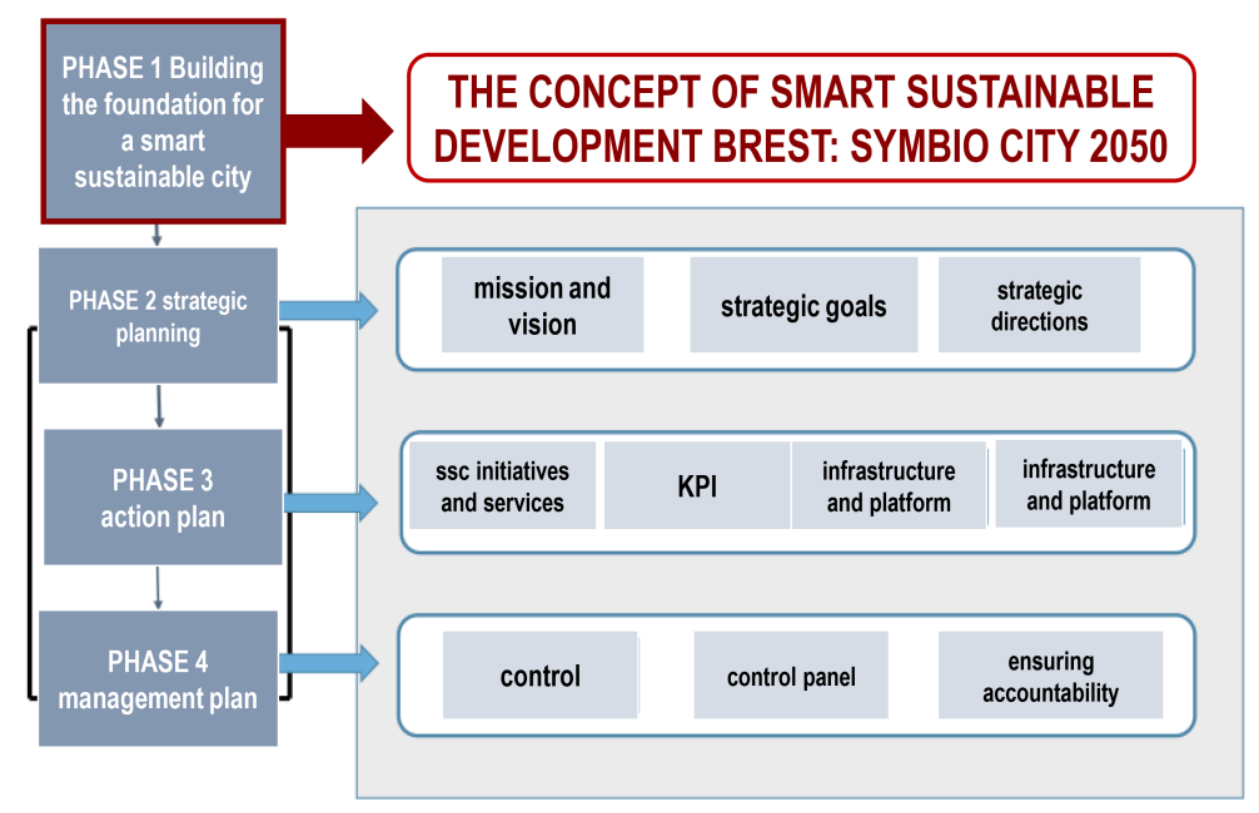

Fig. 2. Concept formation model

The concept was developed in accordance with the provisions of the National Strategy for Sustainable Socio-Economic Development of the Republic of Belarus for the period up to 2030 [6] (in the future until 2035), the Urban Development Policy of the Republic of Belarus for 2016-2020, the legislation of the Republic of Belarus, State, National and regional programs. 


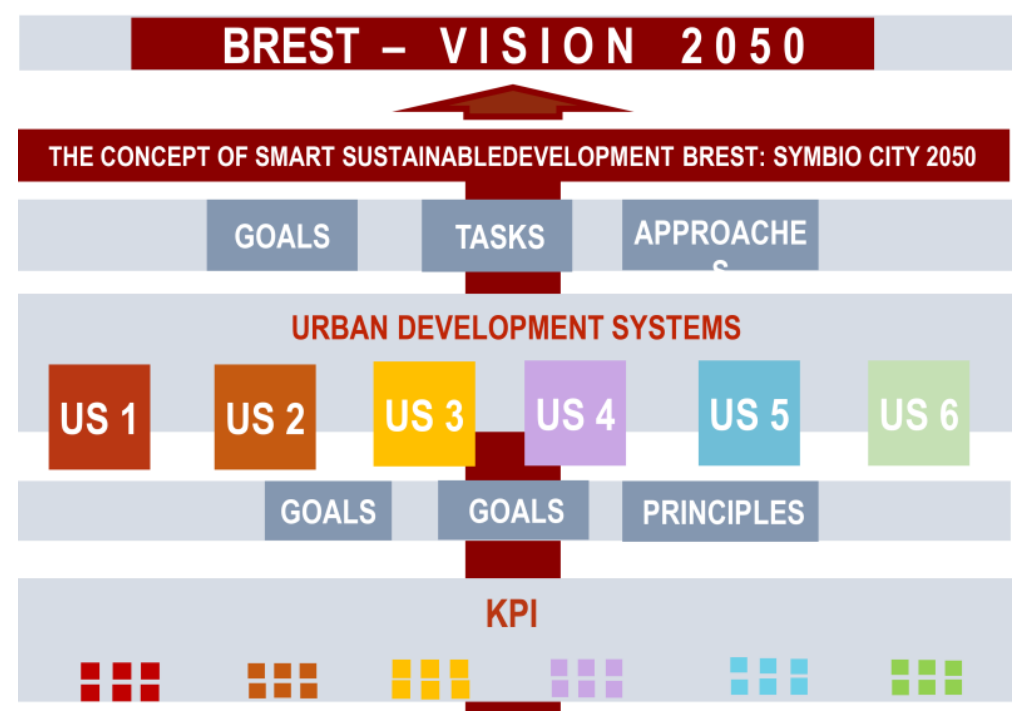

Fig. 3. Concept structure

Its creation and implementation will create conditions for the integrated planning of the development of the city and its infrastructure systems in the short, medium and long term to improve the quality of life of the population, attract investments and innovative development; to connect to this process the current and future state and regional programs, strategies and plans; develop and implement city and sectoral documents based on measurable indicators of both quantitative and qualitative state of development processes; improve existing urban development policies, procedures and practices; develop multisectoral and interdisciplinary collaboration between stakeholders, experience in the integrated actions of all urban systems; provide the citizens of the city - a stable improvement in the quality of life, a comfortable living environment, prosperity, security; territories - a high level of comfort and arrangement of the living environment, conditions for optimal spatial development. At the same time, the conditions for the conservation of resources, the development and productive use of innovations / new technologies, a high, socially balanced quality of life are met [5].

\section{Conclusions}

The described strategic planning documents highlight the priority areas of urban development policy focused on the development and improvement of all spheres of city life on the basis of existing resources. At the same time, they are documents open to suggestions and adjustments aimed at initiating discussions on promising directions and priorities for urban development.

Determining the long-term innovative development of the city they are a tool for coordinating the actions of urban systems, setting priorities for territorial management of energy and climate issues, urban planning and architecture, mobility and organization of traffic, safety, water supply and sanitation, natural resources and waste management.

The presence of an interconnected set of documents (PGC, city development concept, urban planning documentation, urban strategy, and sectoral strategies) and effective management will create conditions for the transition to a high-quality, measurable assessment of urban planning decisions. Cities of Belarus will receive new opportunities for the development of an integrated sustainable urban system that has synergistic links 
between sectors based on energy efficiency, smart land use management, reduced consumption and renewable resources, convenient and efficient transport system, increased prosperity and a multi-faceted cultural identity of society.

\section{References}

1. National Statistical Committee of the Republic of Belarus: demographic and social statistics [Online] URL: http:// www.belstat.gov.by (reference date: 12.06.2020)

2. Planning Sustainable Cities — Global Report on Human Settlements 2009 [Online] URL: http://www.unhabitat.org (reference date: 11.06.2020)

3. 3.EBRD Green Cities[Online] URL: https://ebrdgreencities.com/assets/Uploads/PDF/e0 d6d7606e/Green-City-Action-Plan-Methodology-Russian.pdf. (reference date: 12.06.2020)

4. Belarus: Supporting Green Urban Development in Small and Medium Cities of Belarus (Green Cities) [Online] URL: http://greencities.by/our_project (reference date: 05.06.2020)

5. Ministry of economy of the republic of Belarus [Online] URL: http:/www.economy.gov.by/uploads/files/NSUR2030/ National strategy for sustainable socio-economic development of the Republic of Belarus for the period up to 2030.pdf (reference date: 05.06.2020)

6. Ministry of economy of the republic of Belarus [Online] URL: https://www.economy.gov.by/uploads/files/1061r.pdf (reference date: 05.06.2020) 